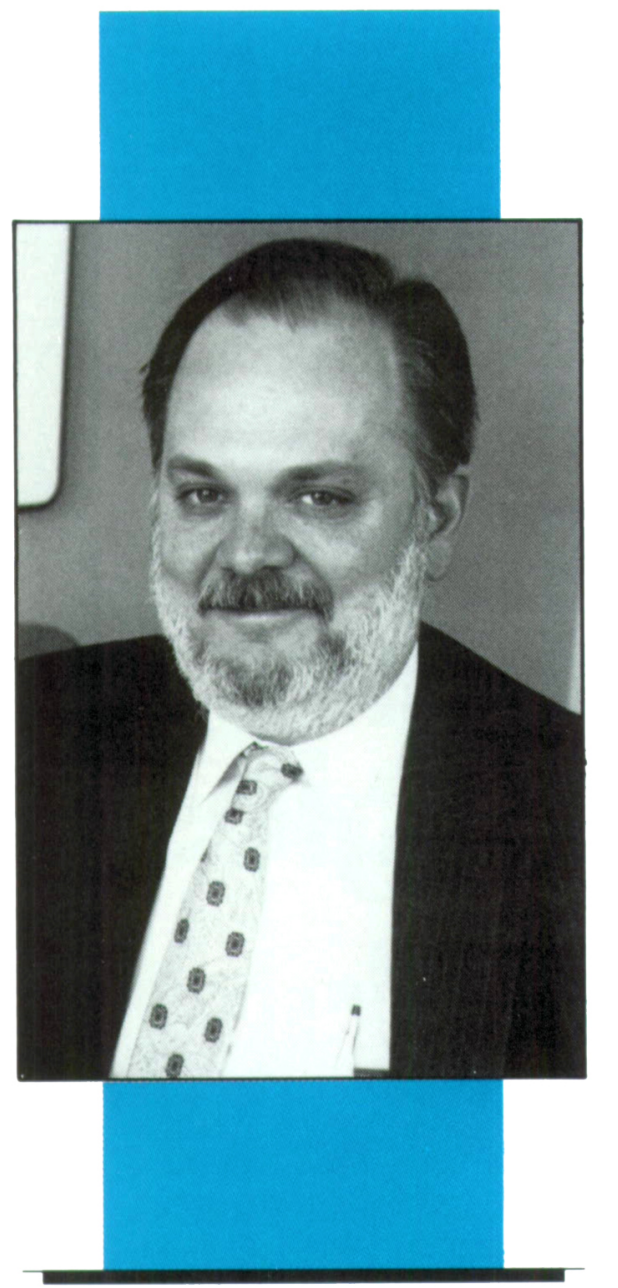

MRS is uniquely positioned to play a major role in the science and technology of a rapidly integrating world economy.

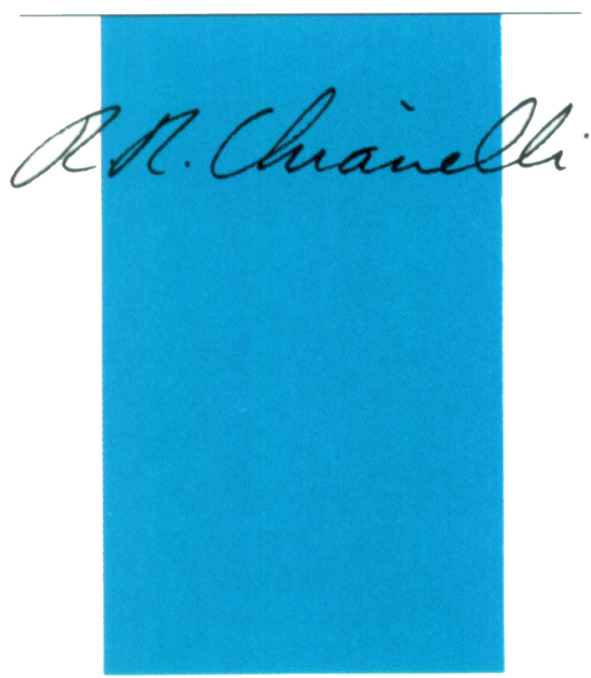

\title{
The 1990s: A Growing International Context
}

It is fitting that the last decade of the 20th century should begin in the midst of events which for most of us who grew up after World War II were only dreams. From the sudden emergence of democracies in Eastern Europe to the tearing down of the Berlin Wall, we watch in awe as the world we knew and learned to live with is flying apart. These events are signaling that World War II is finally over and that the ideas of the West have shown their power in the face of the ideology of communism.

It is also the end of "Pax Americana," that period of time after World War II, unprecedented in history, when the United States enjoyed unparalled prosperity and economic dominance. But as a powerful Japan emerged and Europe began moving toward 1992, we saw this prosperity and dominance slowly eroding in the 1980s. Now with a mixture of apprehension and exhilaration we observe the events in Eastern Europe unfold, and we wonder what the world will be like at the turn of the century.

In the same way the members and staff of MRS look forward and ask, "Where will this organization which has enjoyed such tremendous success and vitality be at the turn of the century?" The answer of course is "wherever it wants to be." I feel confident with this answer because MRS has always gone wherever it wanted to because of the unfaltering vision and commitment of its officers, members and staff. We as an organization have always been exhilarated by the challenge of the future in materials science, and I believe that this excitement will fuel a new decade of growth in MRS.

Because of its history of dedication to interdisciplinary research, MRS is, in my opinion, uniquely positioned to play a major role in the science and technology of a rapidly integrating world economy. In the next decade it will become increasingly clear that countries and corporations can no longer do everything alone. Complex technologies and economic relations will force these entities to take on cooperative and interlocking alliances. A sort of "eco- nomic and technological interdisciplinarity" will be required for success.

To meet this challenge, we at MRS will have to expand our model of interdisciplinary research to include many new fields of materials research. Economic disciplines as related to materials science will become increasingly important as industries and nations struggle with competing materials technologies. Good materials education will play a central role in materials research strategies, and MRS should take the lead.

Environmental issues in materials science will come to the forefront of materials science research in the next decade. It will no longer be enough to produce the best material for a particular application. Industries will be required to adopt "cradle-tograve" strategies for new materials. Older, environmentally unacceptable materials will be replaced with new, safer materials.

Electronic communications will change the face of our meetings, allowing us to simultaneously reach members all over the world. Entirely new concepts of MRS meetings may arise to satisfy the everincreasing desire on the part of policymakers to grasp the meaning of "high tech" materials science. And dominating all this will be a growing necessity for MRS to communicate clearly and effectively to the general public whose daily well-being depends more and more on the product of our research.

All this will occur in a growing international context containing the double elements of competition and cooperation. And there are some who look forward to this next decade with hesitation. But I look forward with excitement and confidence that MRS will be in the "thick of things." The changes now occurring in Eastern Europe are based on ideas "born in the USA" which the world community has adopted as its own. In the same way, I believe, the world materials research community will adopt as its own the idea of the "interdisciplinary spirit," born in MRS.

R.R. Chianelli 


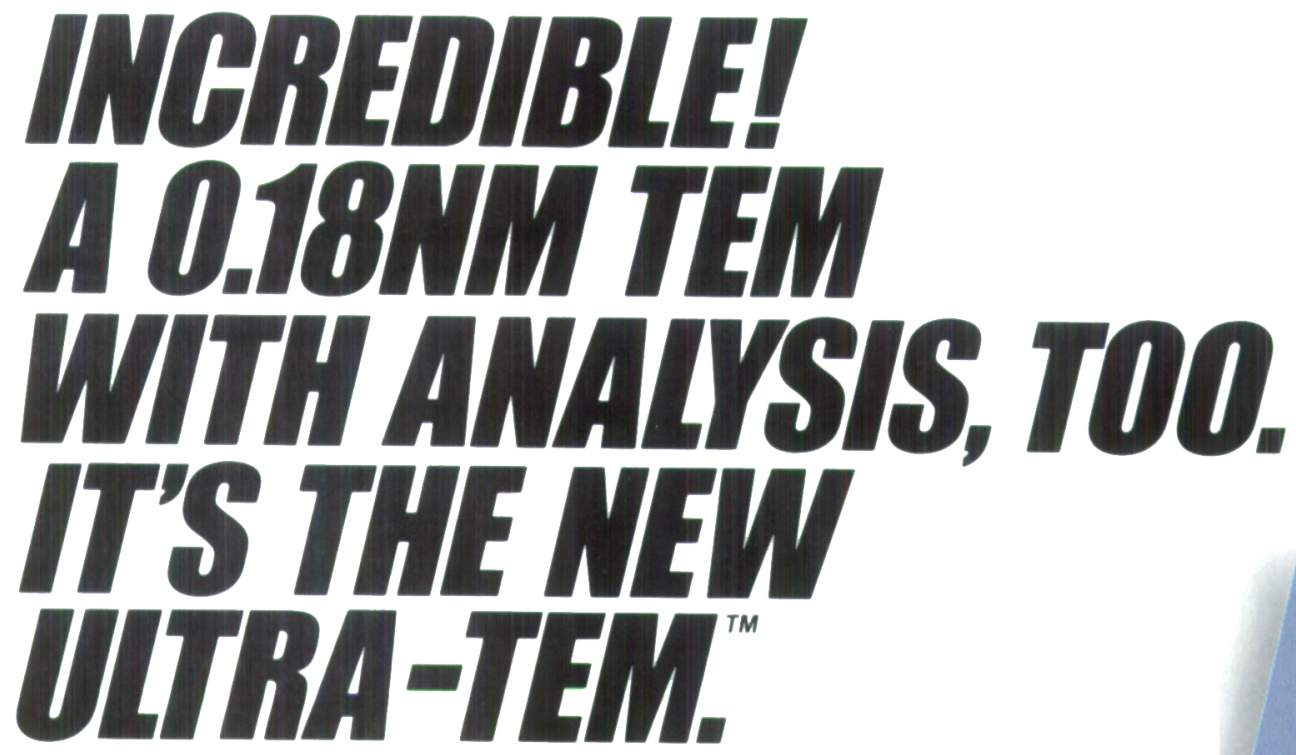

Ultra-TEM. ISI's new Model EM-002B. There's nothing else like it. Anywhere...

Just imagine the TEM work you could do with $0.18 \mathrm{~nm}$ resolution. (And that's at $200 \mathrm{kV}$, by the way, not $400 \mathrm{kV}$.)

Now, imagine that same instrument also giving you nano-probe compositional analysis: EDS. MBED. EELS. CBD.

Not only that, but letting you go from

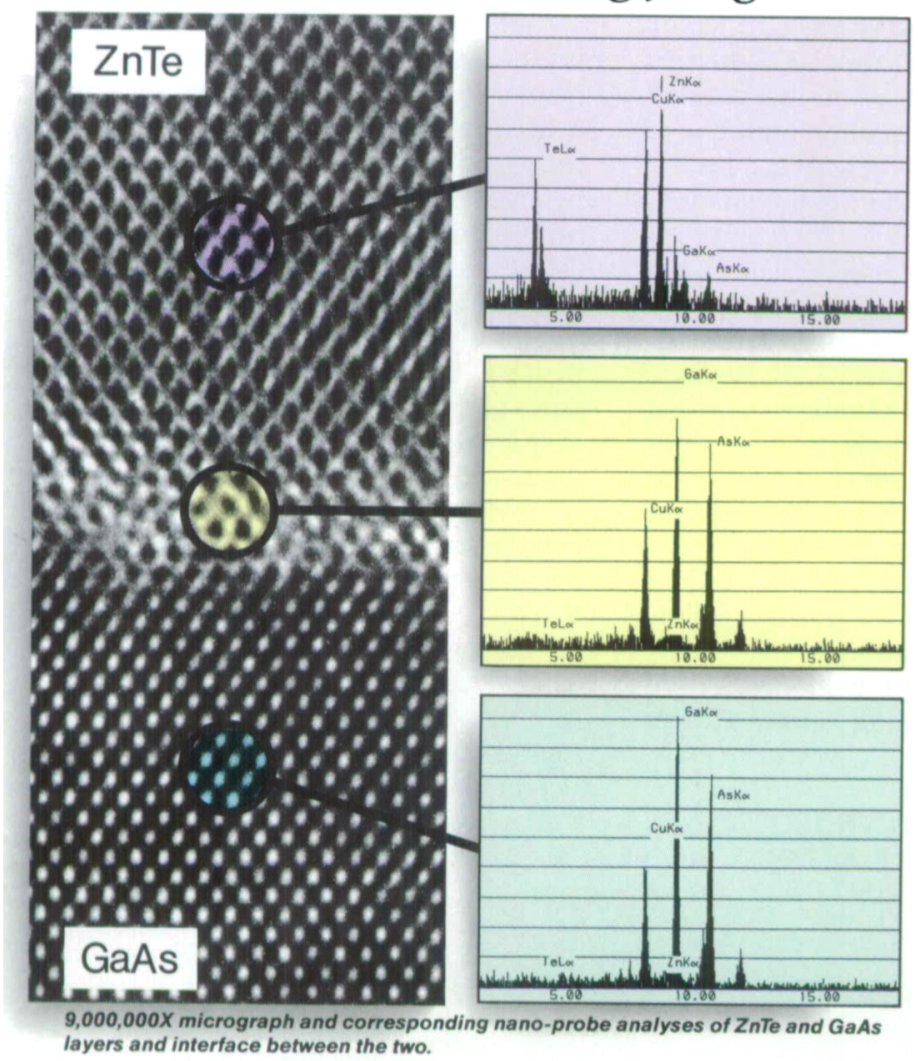

regular imaging to nano-probe. Instantly. At the touch of a button.

So probe placement is always absolutely precise. With no need for scanning attachments.

And as if that were not enough, imagine the Ultra-TEM costing about half what you'd expect to pay for a $0.18 \mathrm{~nm}$ TEM with no analysis...

We consider this new research TEM a pretty significant breakthrough. But we're more interested in your evaluation...

Get all the details on the new UltraTEM Model EM-002B. Call or write, today:

International Scientific Instruments, 6940 Koll Center Pkwy, Pleasanton, CA 94566. (800) 538-6850 or (415) 462-2212. Fax: 415-462-2234.

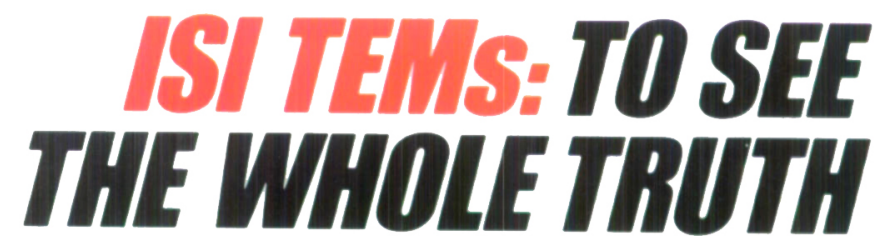

